\title{
EP-73
}

\section{Major vessel bleeding control experience in laparocopic major hepatectomy}

\author{
SangGyun SUH, Kwang-Woong LEE*, Su Young HONG, Eui Soo HAN, Kwangpyo HONG, \\ Jeong-Moo LEE, Suk Kyun HONG, YoungRok CHOI, Nam-Joon YI, Kyung-Suk SUH \\ Department of Surgery, Seoul National University College of Medicine, Seoul, Korea
}

Introduction: Laparoscopic hepatectomy (LH) is worldwidely spread, because LH needs small incision which cause less pain. But during LH, it is hard to control major bleeding. Patient could be in dangerous situation. So we will propose some tips to make control major bleeding during $\mathrm{LH}$.

Methods: The first case had $2.5 \mathrm{~cm}$ hepatocellular carcinoma in segment 5/6. We planned to laparoscopic right hemihepatectomy. After surgery, he had no special event. And he had discharge, at pod 6. The second case underwent low anterior resection due to rectosigmoid colon cancer 6 years ago. He had $3 \mathrm{~cm}$ metastatic colon cancer in liver. We planned to laparoscopic right hemihepatectomy. during surgery, uncontrolled massive bleeding happened, he arrested. So open conversion was done. And he had discharge, at pod 5.

Results: In the first case, there was bleeding during ligation of vessel by hemoloc. We couldn't recognized bleeding focus. So more liver parenchymal dissection was done. We found that inferior vena cava (IVC) which is base of right hepatic vein (RHV) inferior wall was laceration. The operative used laparoscopic surgical stapler for division of RHV and bleeding control. In the second case, liver parenchyma was dissection fully and ready to division the RHV. Operator dissect posterior wall of RHV by golden finger and dissector. At this moment, IVC which is base of RHV was laceration. operator tried to control bleeding by suture IVC. But the patient arrested. Open conversion operator was done.

Conclusions: We suggest laparoscopic surgical stapler rather than manual suture, during massive bleeding. 